\title{
Study of eciency of USAR operations with assistive technologies
}

Quirin Hamp, Omar Gorgis, Patrick Labenda, Marc Neumann, Thomas Predki, Leif Heckes, Alexander Kleiner and Leonard Reindl

\section{Linköping University Post Print}

\section{Tweet}

N.B.: When citing this work, cite the original article.

This is an electronic version of an article published in:

Quirin Hamp, Omar Gorgis, Patrick Labenda, Marc Neumann, Thomas Predki, Leif Heckes, Alexander Kleiner and Leonard Reindl, Study of eciency of USAR operations with assistive technologies, 2013, Advanced Robotics, (27), 5, 337-350.

Advanced Robotics is available online at informaworld ${ }^{\mathrm{TM}}$ : http://dx.doi.org/10.1080/01691864.2013.763723

Copyright: Taylor \& Francis http://www.tandf.co.uk/journals/default.asp

Postprint available at: Linköping University Electronic Press http://urn.kb.se/resolve?urn=urn:nbn:se:liu:diva-80381 


\title{
Study of efficiency of USAR operations with assistive technologies
}

\begin{tabular}{|c|c|c|}
\hline \multicolumn{3}{|l|}{ Quirin Hamp*, } \\
\hline Thomas Predki ${ }^{\nabla}$, & Leif Heckes ${ }^{\nabla}$, & Kleiner $^{\diamond}$ and \\
\hline \multicolumn{3}{|c|}{ Leonhard Reindl ${ }^{\star}$} \\
\hline University of Freiburg - IMTEK $K^{\star}$ & University of Linköping ${ }^{\triangleright}$ & Ruhr-University Bochum ${ }^{\nabla}$ \\
\hline Department of Microsystems Engineering & Department of Computer Science & Faculty of Mechanical Engineering \\
\hline Laboratory for Electrical Instrumentation & AIICS Division & Chair of Engineering Design \\
\hline 79110 Freiburg, Germany & 58183 Linköping, Sweden & 44801 Bochum, Germany \\
\hline Phone: +497612037158 & Phone: +4613281509 & Phone: +49 2343222477 \\
\hline quirin.hamp@imtek.uni-freiburg.de & alexander.kleiner@liu.se & labenda@lmk.rub.de \\
\hline
\end{tabular}

\begin{abstract}
This paper presents presents a study on efficiency of Urban Search and Rescue (USAR) missions that has been carried out within the framework of the German research project I-LOV. After three years of development, first field tests have been carried out in 2011 by professionals such as the Rapid Deployment Unit for Salvage Operations Abroad (SEEBA). We present results from evaluating search teams in simulated USAR scenarios equipped with newly developed technical search means and digital data input terminals developed in the I-LOV project. In particular, USAR missions assisted by the "bioradar", a ground-penetrating radar system for the detection of humanoid movements, a semi-active video probe of more than $10 \mathrm{~m}$ length for rubble pile exploration, a snake-like rescue robot, and the decision support system FRIEDAA were evaluated and compared with conventional USAR missions. Results of this evaluation indicate that the developed technologies represent an advantages for USAR missions, which are discussed in this paper.
\end{abstract}

keywords: USAR, efficiency, information management, technical search, radar, endoscope, emergency communications.

\section{Introduction}

To increase the efficiency of Urban Search And Rescue (USAR) missions is a challenging problem that is unstructured and is requiring a multi-criteria optimization that satisfies multiple partially conflicting objectives. Disasters such as earthquakes or tsunamis represent a particular challenge since the size of 
the destroyed terrain and the number of affected persons requires means of response that are difficult to plan ahead of time.

Most of the easily accessible victims after such a disaster are rescued by first-responders such as passersby. Coburn and Spence estimate that $90 \%$ of entrapped victims can be rescued before professional USAR teams are on-site [1]. The remaining entrapped survivors are often difficult to be found since they are unable to alert the emergency workforces. Either they are unconscious or they are entrapped behind so much debris that their distress calls cannot be heard by humans. In addition, after a entrapped survivor has been found, the extrication efforts are considerable and require in average $10 \mathrm{~h}$ depending on the situation of entrapment [2]. Unfortunately, in the first $72 \mathrm{~h}$ during which the probability of rescuing trapped survivors is reasonably high [3], the resources are expected to be limited [4]. Hence, a prioritization of activities in mass casualty events is recommended to assure an optimal rescue success [5] while hazards for rescuers should be kept to a minimum.

The increase of rescue efficiency of entrapped survivors through prioritization is dependent on the ratio of found over total number of entrapped survivors and on an accurate estimation of the extrication effort for their rescue. Furthermore, during operations with several teams having various competencies, prioritization requires coordination. This coordination is possible if communication between responders in the field and the coordination authority -i.e., the Emergency Operation Center (EOC)- is efficiently managed.

The technologies presented within this paper have been developed in the scope of the I-LOV project that stands for "intelligent, securing locating system for the rescue and extraction of trapped victims". The project aims on both the improvement of technical search capabilities, and the improvement of information management during USAR missions. The technologies of the project have been developed in collaboration with the German Federal Agency for Technical Relief (THW). The novel search technologies are: a robotic platform (Fig. 1a) carrying a modular sensor suite [6], a video camera mounted on a stiffening hose, a system for localization of GSM phones (Fig. 1b) within a cell [7] and a radar system for detection of humanoid movements such as breathing (so called "bioradar") which has been employed during the Haiti earthquake response operations in 2010 [8].

The newly developed search technologies and the conventional ones can be categorized into three categories which capabilities are dependent on the circumstances of the entrapment and on their application. These three categories are represented schematically in Fig. 2. This categorization is of importance since it determines how search results can be respected in the prioritization process.

The first category can be subsumed under "detection" methods. It produces a binary result whether or not a entrapped survivor - unable to alert rescuers- is within the scan volume of the method with a detection probability $P<1$ such as for instance canine search when the dog cannot access the victim. The second category are "localization" methods that not only produce a binary result, but also spatial information such as a direction, a range measurement, or even the position. The search of cellular phones is for instance a method which could be categorized as localization method. The third method differentiates itself from the previous two categories that it produces evidence $(P=1)$ about 


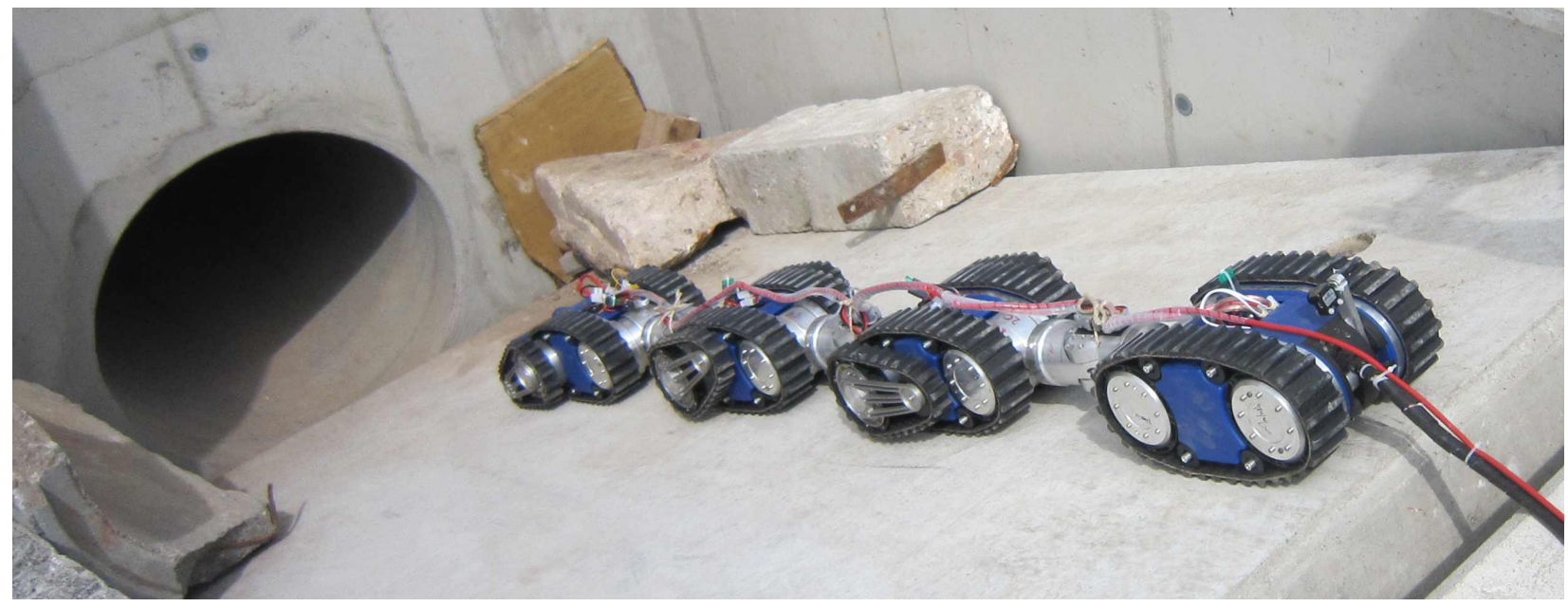

(a) USAR Robot Moebhiu ${ }^{2}$ s entering in a sewer system.

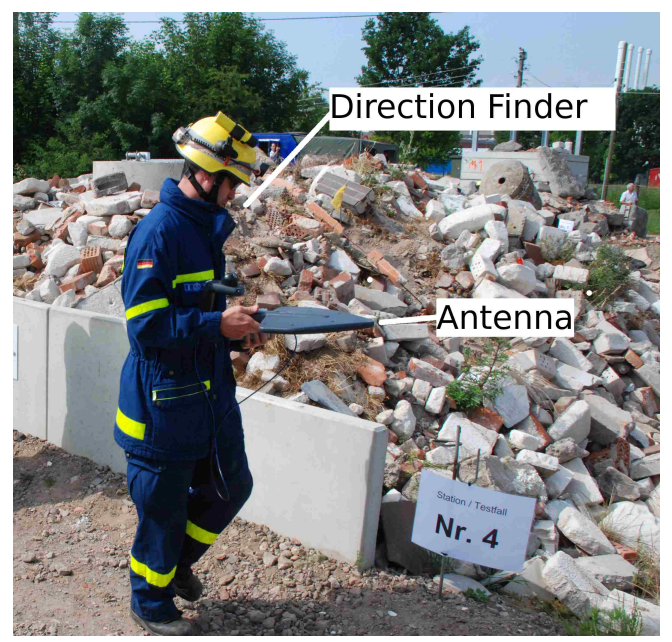

(b) GSM phone localization.

Figure 1: Search technologies developed in the framework of the I-LOV project during evaluation at a simulated disaster site in Hoya, Germany, 2011.

the existence of a survivor. Search methods of this category are so called "verification" methods. Visual inspection with rescue robots or endoscopes can be considered as verification methods and produce certainty about the position of a victim.

Detection methods are used for initial exploration that estimates the total number of entrapped victims. Besides the detection and false alarm rates, the performance of these methods is determined by how much surface can be scanned in what time, called search speed. The second and third method -if their search speed is low- should be employed to reduce false alarms and the extrication effort. The extrication effort can be reduced with an accurate position estimate of the survivor because an optimal approach to reach the sealed void in which the survivor is located can be deduced with this position.

The key to efficient operations is not only the gathering of accurate information, but also adequate presentation and dissemination that contributes to enhance a collective situational awareness. Espe- 


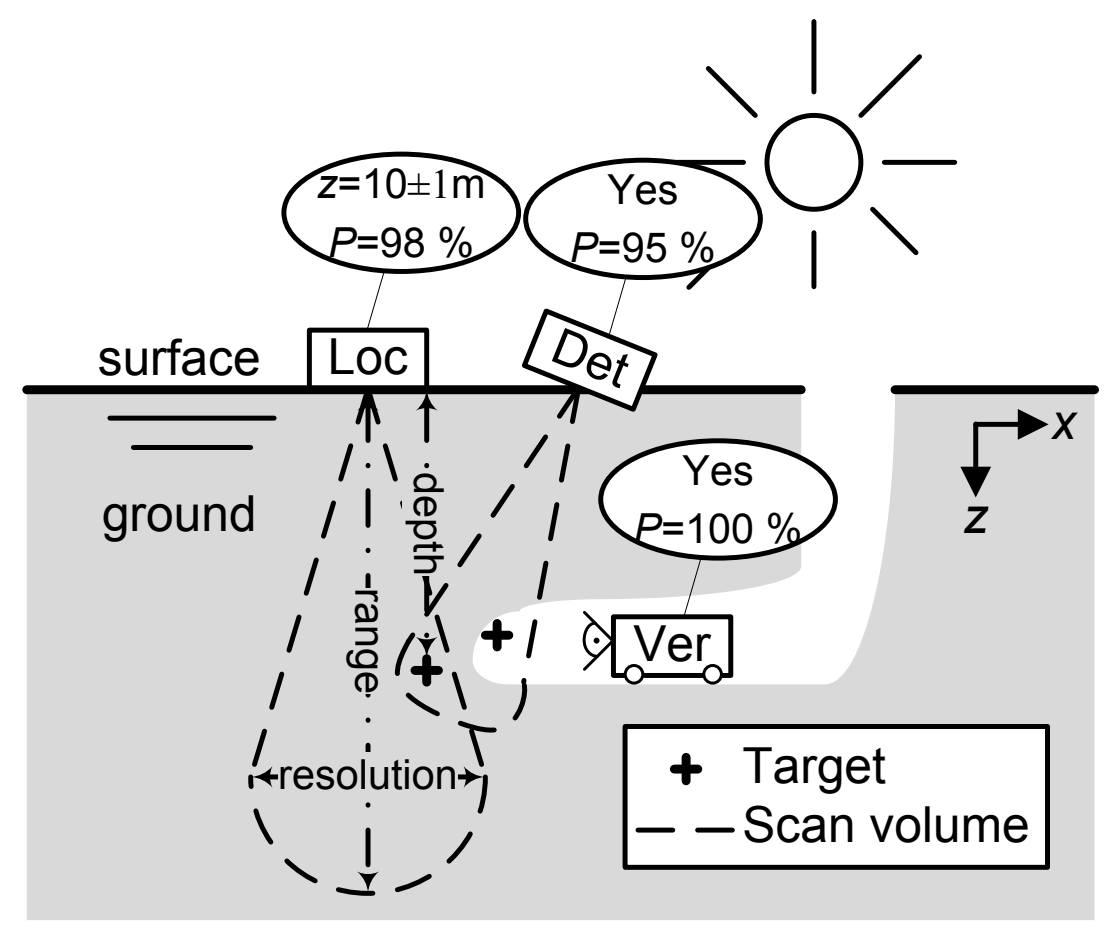

Figure 2: Three different classes of search methods: Localization, Detection, and Verification methods.

cially during USAR operations, the collection and presentation of uncertain information from various sources is challenging. A Decision Support System called FRIEDAA ${ }^{1}$ has therefore been developed that additionally has the capability to fuse uncertain information about positive and negative results of search activities [9]. The volume and the heterogeneity of search results seem to be overwhelming for emergency workforces [10]. This fusion aims at improving the accuracy of the position estimate of the entrapped survivor and therefore allows to reduce extrication effort.

The goal of this paper is to report whether the new assistive technologies have potential to increase a USAR mission's efficiency based on first field tests during which these novel approaches for victim localization and information fusion have been deployed. The evaluation was performed by professional USAR workforces of the THW and in particular of the Rapid Deployment Unit for Salvage Operations Abroad (SEEBA) which is trained for assistance in international disaster response.

The reminder of this paper is structured as follows. In Section 2 state-of-the-art protocols of USAR operations are discussed. In Section 3 the technical tools developed in I-LOV are introduced and experiments for testing their deployment by professional response personnel are presented in Section 4. Finally, achieved results and lessons learned are discussed in Section 5.

\footnotetext{
${ }^{1}$ Short for "Functional Remote Information Exchanger with Developing Aggregation Algorithms" IT-system
} 


\section{State Of the Art of USAR Operations}

USAR research in Germany was firstly initiated by Maack during WWII [11-13]. He suggested the five phase strategy procedure for finding victims, which aims to ensure high efficiency while decreasing risks for rescuers and trapped survivors. This procedure is nowadays still used by German rescue organizations during USAR missions [14], but has another order than the prioritized one during the USAR operations after the World Trade Center (WTC) collapse in New York 2001 (see [15] p. 380). After first actions (phase I) and the rescue of "surfaced victims", i.e., victims that are easily accessible (phase II), the search for trapped victims is initiated (phase III). If canine search is available, it is the first method of choice. Two to three dogs are conventionally employed. The second dog validates positive search results of the first one. The third dog is used if the other two dogs are exhausted or in order to check after the extrication of a victim whether another one has been forgotten. If the results of the canine search are uncertain, for example when both dogs showed different reactions at the search site, technical search means -if available- are used to verify the results of the dogs. Standard equipment of the THW are acoustic devices. During phase IV trapped victims are extricated. Only after the exhaustive search has been concluded, the area is cleared for systematic removal of heavy debris (phase V).

Operational progress monitoring is commonly based on radio communications or personal messengers. The information is logged in chronological order and highlighted on a tactical map which usually is based either on an aerial image or on a schematic sketch such as presented in Fig. 3. Information categories are differentiated through tactical symbols which are defined in guideline DV1-102 [16].

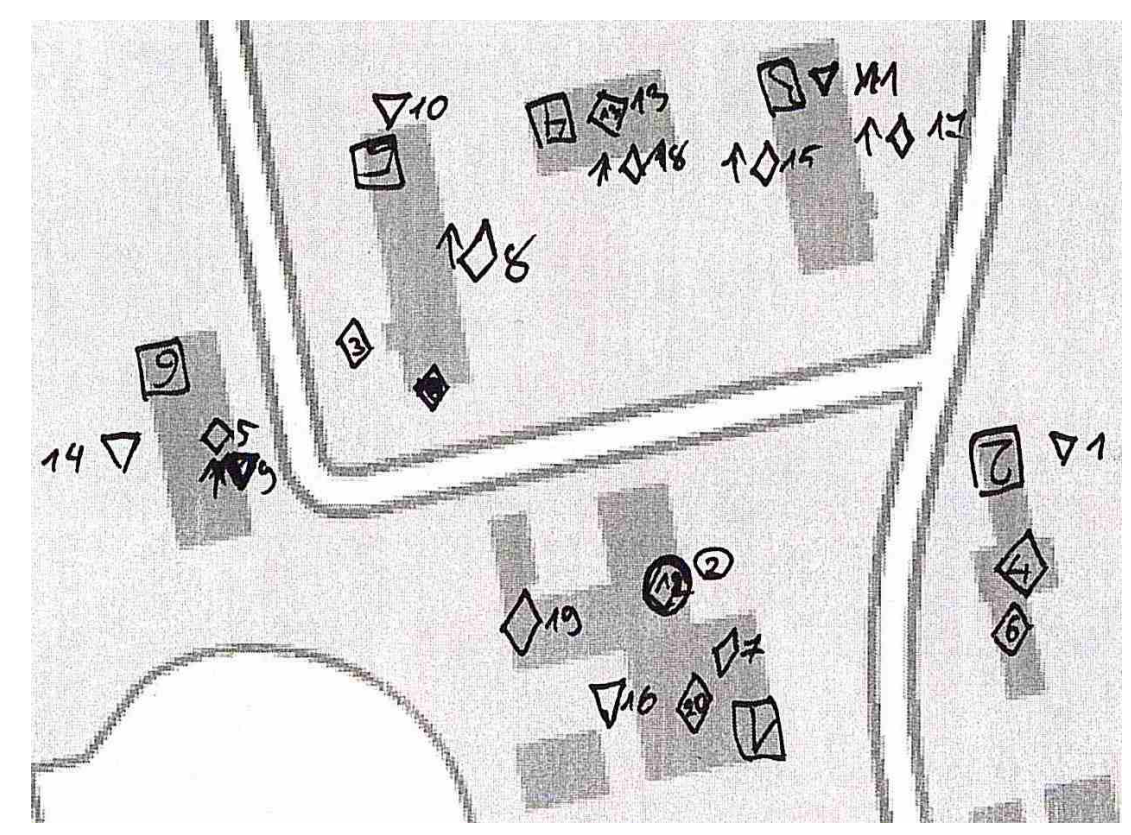

Figure 3: Conventional map of operational progress during a field test (see Sect. 4.1 on p. 10) in 2011 Holzwickede, Germany. 


\section{Evaluated technologies of the I-LOV project}

Four components of the I-LOV project were evaluated during the field tests: the bioradar system, the video probe, a rescue robot and the IT-System FRIEDAA ${ }^{2}$. These components will briefly be described in the following.

\subsection{Bioradar}

The "bioradar" system is a ground-penetrating radar (GPR) system which enables the detection of repetitive movements such as the heart beat and the chest movement during respiration [8]. Therefore, the bioradar is capable of detecting the presence of either conscious or unconscious survivors situated behind obstacles. The bioradar is a device which antenna needs to rest immobile on the rubble pile during an approximatively $30 \mathrm{~s}$ long scan in order to detect human movements of $0.3-4 \mathrm{~cm}$ amplitude. The device is portable by rescue personnel $(\sim 6 \mathrm{~kg})$ and has to be placed above the estimated position of the trapped victim as illustrated in Fig. 4a. The system is composed of antenna, energy supply unit and integrated circuit board implementing the high-frequency part. The control unit is implemented by a laptop suitable for field use. The laptop is also utilized for the signal processing of the digital raw signal data processed by the circuit board and its graphical representation is shown in Fig. 4b.

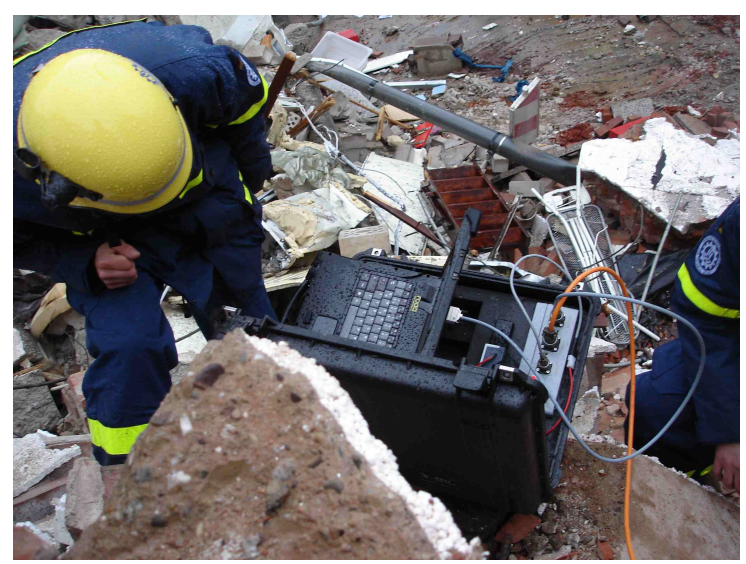

(a) The bioradar antenna is placed on top of the rubble pile for victim detection.

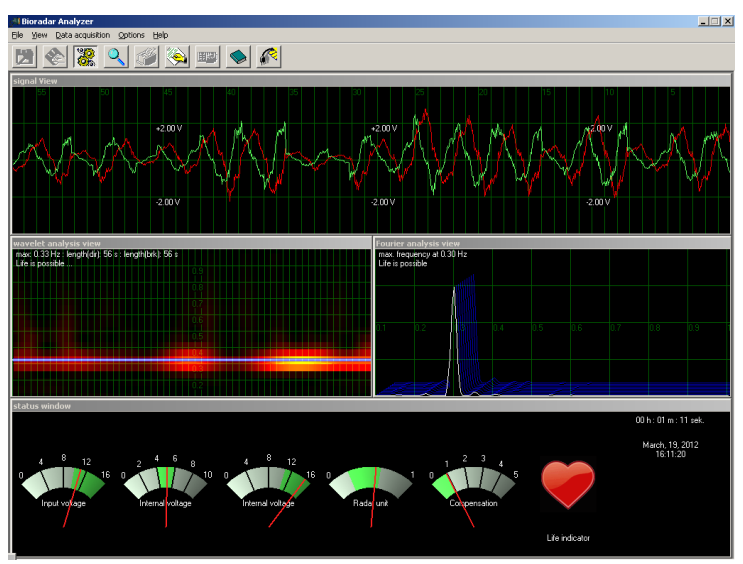

(b) User interface of the bioradar with analysis in time and frequency domain, control panel, and binary output on the bottom right (heart).

Figure 4: The bioradar antenna in the field and its graphical user interface for the interpretation of the measurement results.

\subsection{Semi-active Video Probe}

Passive endoscopic devices such as the telescopic steerable cameras or fiber-optical devices are frequently used for USAR. However, one drawback of this technology is the lack of penetration capabilities within

\footnotetext{
${ }^{2}$ short for "Functional Remote Information Exchanger with Developing Aggregation Algorithms"
} 
constrained environments such as dense rubble piles. A consequence is that their penetration depth is very limited, usually below a couple of meters. New developments such as the active scope camera of $4 \mathrm{~m}$ length presented by Hatazaki et al. bypasses these limitations [17]. However, another limitation of this device is the user interface, which does not provide any information on position and orientation of the head. This can cause the user to easily loose orientation and thus impede to localize observations within the rubble pile. This has been identified by Casper et al. as major disadvantage during robotic USAR at Ground Zero after the WTC collapse [15].

Therefore, a semi-active, waterproof video probe has been developed in the scope of the I-LOV project that solves these issues. It consists of the following three main components: The first component is a hose of variable length $(5-30 \mathrm{~m} \times \varnothing 65 \mathrm{~mm}, \sim 1 \mathrm{~kg} / \mathrm{m})$ that can be controlled in its stiffness through air pressure (max. 8 bar) (see Fig. 5). The video probe can be pushed using this hose up to $10 \mathrm{~m}$ into the rubble pile by a single human user from outside. The second component $(600 \mathrm{~mm} \times \varnothing 65 \mathrm{~mm}, \sim 3.4 \mathrm{~kg})$ allows the positioning of the head component carrying the video camera through pitch and yaw. The video camera and LED illumination in the head component (300 mm $\times \varnothing 80 \mathrm{~mm}, \sim 2.5 \mathrm{~kg}$ ) can be oriented trough two additional degrees of freedom (roll and yaw). The steering of the probe during insertion is performed through the three joints and the so-called "Lindauer Schere", which enables the probe to contrive in a bifurcating propagation channel by ejecting and retracting a structure at the distal part of the head. Sensors for artificial horizons are placed in the second component and in the head, respectively. By this, enhanced situational awareness is offered to the user, for example, when penetrating dense rubble piles, which also enables the localization of observations during the search.

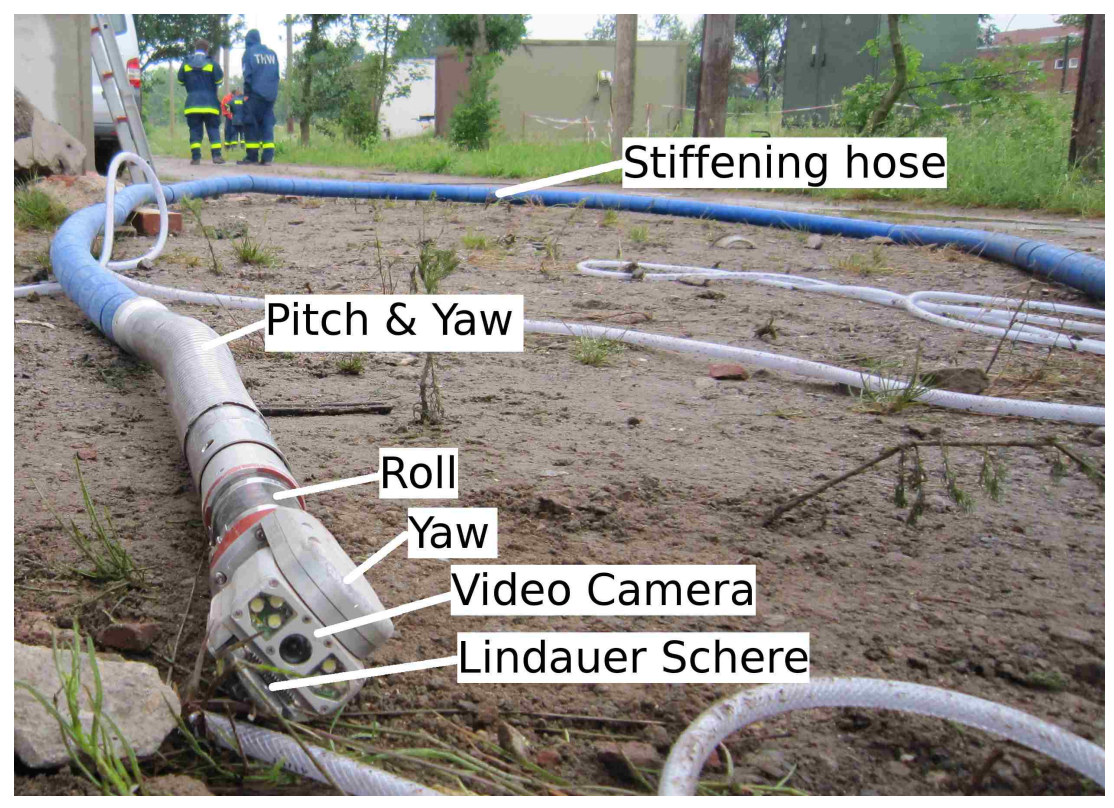

Figure 5: Semi-active video probe that can travel up to $10 \mathrm{~m}$ rubble. 


\subsection{Rescue robot for USAR}

Mobile robots for exploration of hazardous environments must possess enhanced rough terrain mobility and outstanding locomotion capabilities [18]. They must have the ability to negotiate various types of obstacles such as high steps and wide gaps and maneuver in confined space. Conventional track or wheel driven single-body robots either have the required mobility but are too big to turn in narrow spaces or are small enough but fail at successfully tackling obstacles. The single-body robots such as Quince or RHex are a good compromise between mobility and terrainability [19,20], but will never excel in all kind of terrains.

In comparison, systems that are biologically inspired by snakes or worms solve both problems [21] and might even fulfill more tasks [22]. They feature a modular and flexible structure as well as numerous degrees-of-freedom, enabling the system to adapt to the terrain. The kinematic redundancy of the structure of these type of robots enables them to handle obstacles.

Within the I-LOV project a snake-like robot was developed that is composed of four approximately identical modules that are coupled by three active joint units (see Fig. 6).

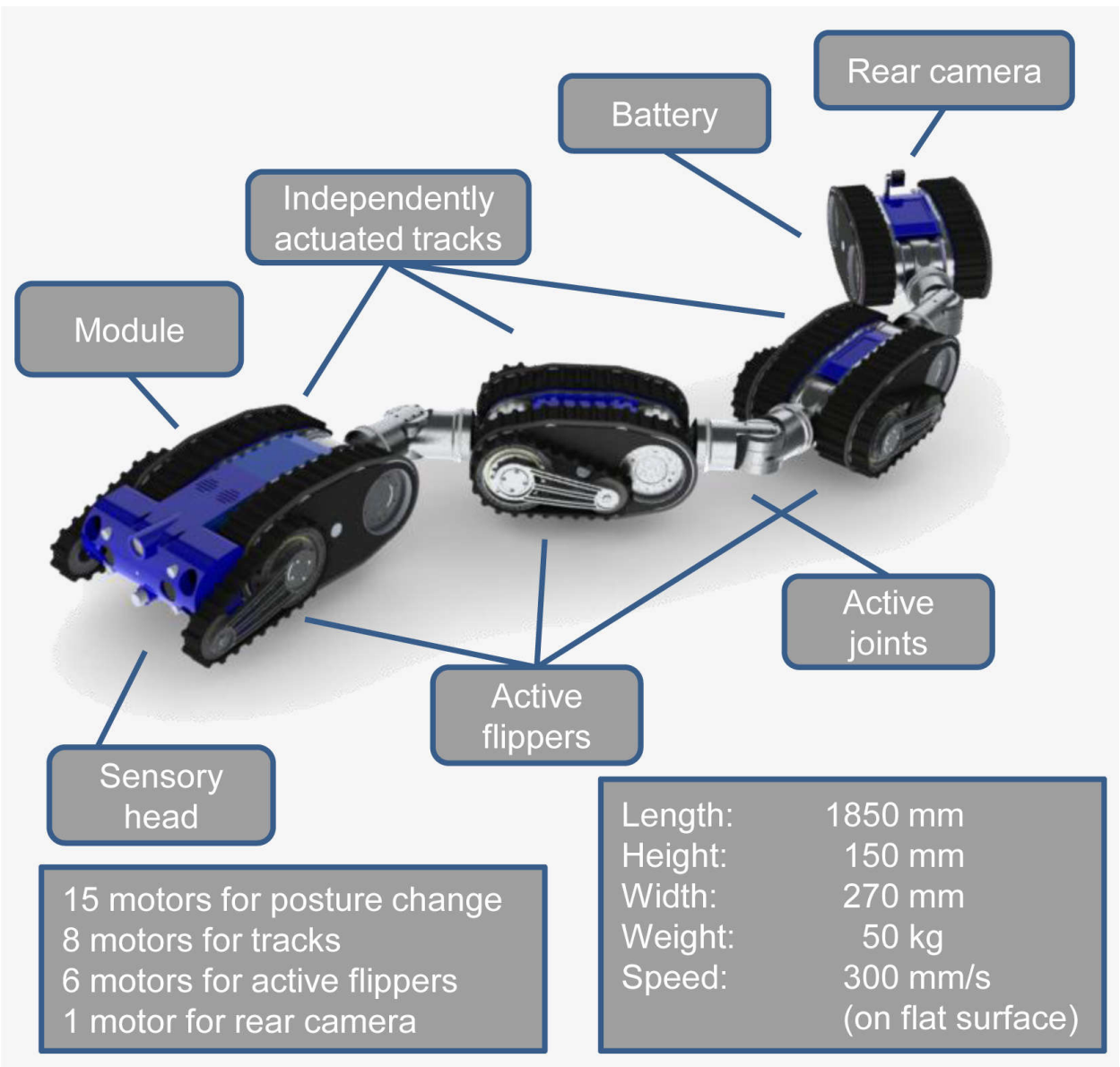

Figure 6: Components of the snake-like Rescue Robot Moebhiu² s for USAR tasks.

Each module is equipped with two independently actuated tracks on both sides which are used not only for the system's propulsion but also for its steering and maneuvering. In addition to the 
given tracks the first three modules are equipped with two active flippers which increase the tractive power of the system. The active joint units offer five rotative degrees-of-freedom which are basically responsible for the system's abilities to negotiate remarkable obstacles as well as to adapt its posture and configuration for traction optimization. The five rotation axes of the active joints are arranged serially and enable following movements: pitch, roll, yaw, roll, pitch. The system is symmetrical thus can operate upside-down.

The robot can be tele-operated and possesses semi-autonomous capabilities in form of shared control. In order to realize the semi-autonomy, the system is equipped with multiple tactile sensors, enabling the comprehension of the system's interaction with its environment.

For victim localization, the robot carries a modular and exchangeable sensory head which can be equipped with diverse external sensors. Our basic configuration features a stereoscopic camera, an infrared camera, distance sensors, a $\mathrm{CO}_{2}$-sensor, two-way audio, and illumination. Additionally, the first module is equipped with an inertial measurement unit for navigation, a WLAN interface for communication as well as the control unit. On the fourth and last module is mounted a tilting rear camera. It also carries the robot's batteries for electrical power supply.

\subsection{Decision Support System FRIEDAA}

The advantages of the use of so called geographic information systems (GIS) have already been recognized and used in projects such as the Japanese DDT project [23]. The collection of relevant information by collaborating operational units and the centralized storage assures enhanced situational awareness. However, GIS are typically limited to store information from reliable observation sources only, whereas in the context of USAR uncertain observations are likely to occur. FRIEDAA is an extension to state-ofthe-art GIS that deals with observation uncertainty. FRIEDAA enables rescue workforces, for example, to collect and evaluate uncertain information about victim whereabouts. Information from eye-witnesses and uncertain and imprecise results of search efforts can be collected and attached with geo-reference and timestamp similar to the Kiwi+ format presented by Meguro et al. [24]. For on-site emergency workforces, information collection is facilitated through a Personal Digital Assistant (PDA) application called GeoRescue that allows user inputs by a pointing stick (Fig. 7b). The acquisition of geo-references is performed automatically through a GPS receiver. To circumvent the known lacking precision of GPS (see [25]), relative input can be performed or corrected through drag and drop of tactical symbols in the desktop application of FRIEDAA. Furthermore, it enables visualization of multiple horizontal planes in order to track the operational progress in semi-collapsed, multi-storied edifices.

Three main functions assist the Search and Rescue (SAR) team during decision-making. First, there is the handling of the victim list which allows for a comparison of victims that were already found and victims that are still expected to be found. Second, for likely victims several search methods can be employed that are all generating results. Multi-level information fusion ${ }^{3}$ allows to associate reports,

\footnotetext{
${ }^{3}$ refer to Nakamura et al. for the definition [26].
} 
e.g., from eye-witnesses, that concern the same victim. Furthermore, a victim detection algorithm asses all associated information and finally infers an estimated target location. Third, the positions of rescue forces are assessed automatically, e.g., whether they are within hazardous zones. In specific cases an alert is triggered.

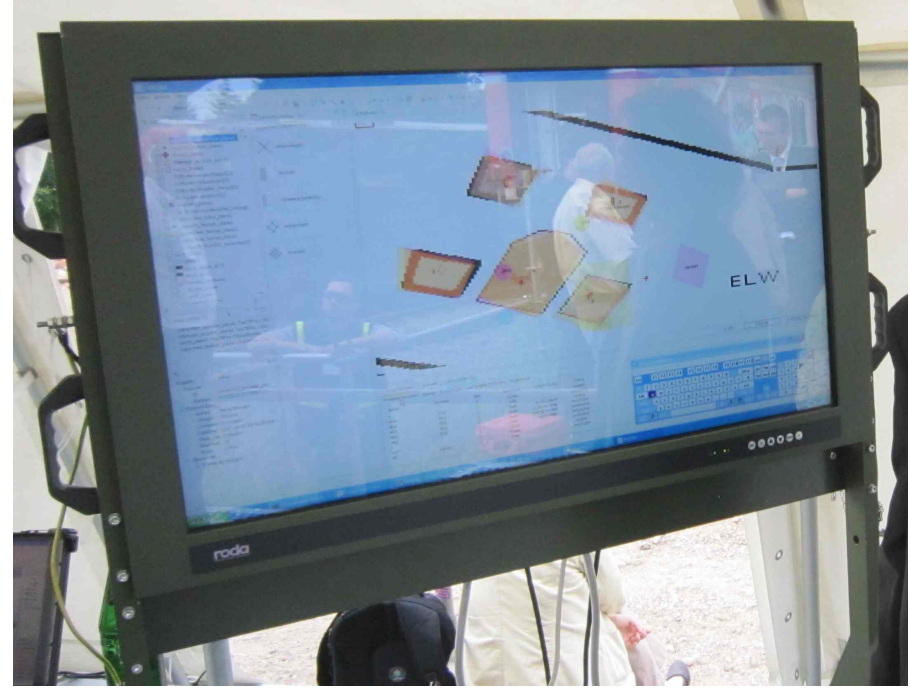

(a) FRIEDAA GIS application on a 46 inch, tactile screen in the EOC.

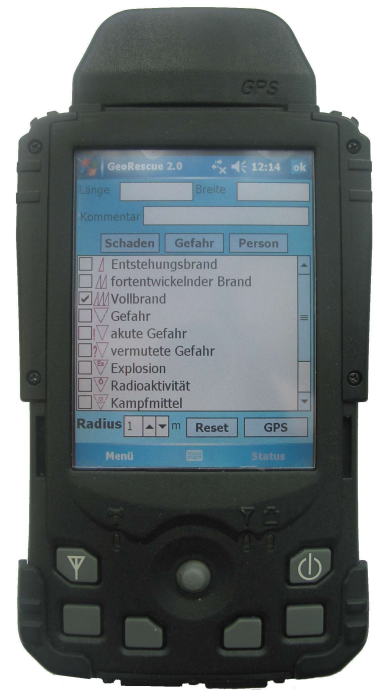

(b) GeoRescue application on a PDA with GPS receiver enabling the collection of georeferenced, USAR relevant information.

Figure 7: Decision Support System FRIEDAA for USAR operations during a field test in 2011 at the German Federal School of the THW in Hoya, Germany.

\section{Field test results}

Two field tests have been carried out by SAR professionals to evaluate the proposed methods of the ILOV project. The first field test focused on the benefits of FRIEDAA during the response to large scale incidents. Especially, communication performance was assessed based on the number of messages $N_{\text {mes }}$. The second field test allowed to evaluate the new search technologies. In order to facilitate objective comparisons, both experiments were carried out within two runs, on the one hand with assistive tools of the I-LOV project, and on the other hand without.

\subsection{Evaluation of FRIEDAA for large-scale disasters}

The first field test was carried out in an intact environment of approximatively 3.7 ha that was explored in parallel by four SAR teams (two persons, one team assisted by search dogs) in Holwickede, Germany. In addition to the outside surface, there were six buildings that had as well to be explored indoors (see Fig. 3 for a tactical map). Four of the edifices had two floors. The aim was to find 23 cards (three with 


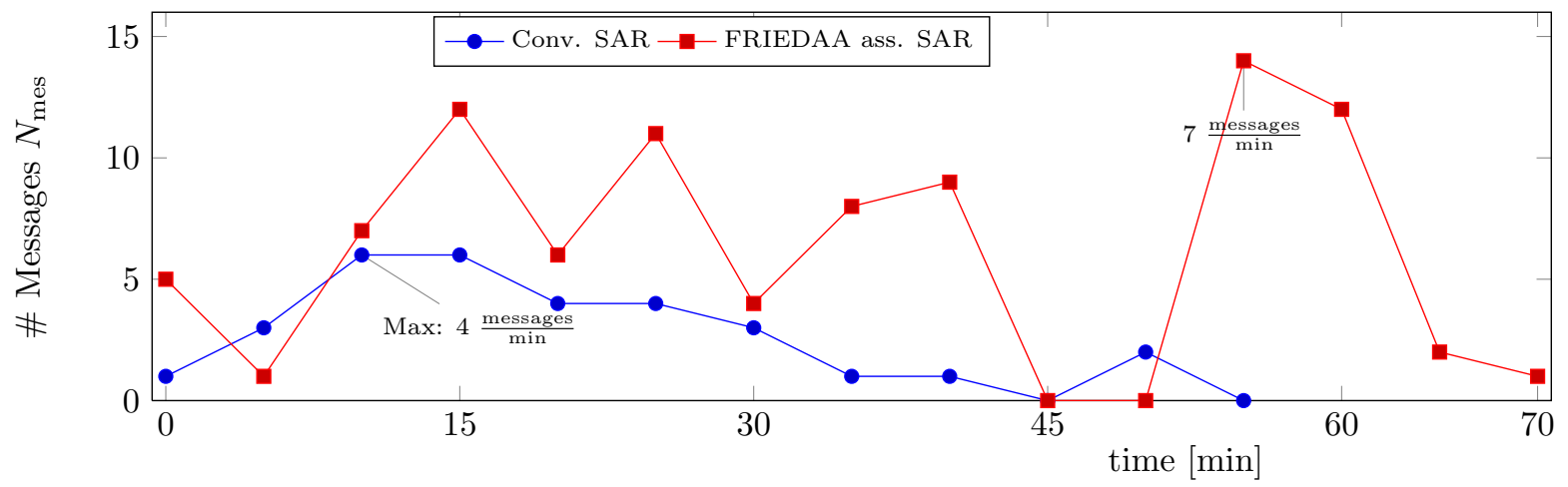

Figure 8: Comparison of the message volume $N_{\text {mes }}$ treated by the EOC between the first and the second run with respect to the duration of the search. The amount of messages that can be managed assisted by FRIEDAA is higher than for conventional SAR.

uncertain information) and three human victims which were mainly hidden within the buildings. Half of the cards were concerning hazards, the other half victims.

In particular, the EOC was under observation. The first run employed a conventional radio communication infrastructure, the second one was additionally assisted by the FRIEDAA communication infrastructure based on commercial WLAN. During the first run, two SAR operation leaders were in the EOC and managed the operational progress. One was logging all incoming messages chronologically, the other person was busy with plotting information on the map presented in Fig. 3 and with updating a table for better presentation of the information.

The second run employed the same setting, but the teams were assigned to regions they had not explored in the previous run. All search teams carried a PDA with them that they used preferentially to collect and transmit information to the EOC using the GeoRescue application.

During the first run 31 radio messages were transfered in $52 \mathrm{~min}$ as presented in Fig. 8. The two persons in the EOC had difficulties to handle this amount of incoming messages, which resulted in delays of approximately $5 \mathrm{~min}$. The maximal information flow treatable by the EOC was about four messages per minute. A comparison of the map in Fig. 3 with the actual situation resulted in the fact that during the first run two victim observations and three hazard observations were missed. Furthermore, the locations of the observations were only approximative and did not correspond to the actual positions since emergency workforces only indicated the geographic direction and the floor.

The second run lasted in total 69 min during which 57 messages were received by the EOC. Considering the fact that the GeoRescue application allows to transfer messages containing multiple data (e.g., a hazard combined with information about a person) and that during the previous run every single radio communication message was accounted for, a total of 92 successfully transmitted messages has to be considered. Every time an information was collected by the EOC, the region around the acquired geo-reference was automatically marked as cleared by FRIEDAA, which increased the amount of messages to 149 in total. In Fig. 8, messages about cleared zones are not accounted for, because they were 
automatically sent. The identification of the search team was as well transferred automatically to the FRIEDAA system.

Since the WLAN network did not cover the whole area, messages were sent delayed, e.g., once a position within communication range has been reached again after loosing connection. Furthermore, the lacking GPS reception indoors constrained the SAR team members to locate themselves near windows to receive GPS signal. They had to indicate whether the message concerned the first or the second floor. The search performance much improved when FRIEDAA was deployed. Only one hazard was missed. A comparison of the performance of both runs is presented in Table 1.

Table 1: Performance of the two runs evaluating FRIEDAA for large scale disasters.

\begin{tabular}{|l||l|l|l|l|}
\hline Run & $\begin{array}{l}\# \quad \text { Infos } \\
\text { Missed }\end{array}$ & $\begin{array}{l}\text { Avg. \# Mes- } \\
\text { Sages }\left[\mathrm{min}^{-1}\right]\end{array}$ & $\begin{array}{l}\text { Avg. Delay } \\
{[\mathrm{min}]}\end{array}$ & $\begin{array}{l}\text { Total Search } \\
\text { Time }[\mathrm{min}]\end{array}$ \\
\hline \hline CONVENTIONAL & 5 & 0.60 & n.a. & 52 \\
\hline FRIEDAA & 1 & 2.16 & 8 & 69 \\
\hline
\end{tabular}

\subsection{Evaluation of assistive search technologies integrated in conventional USAR procedure}

The second field test took place in a completely destroyed area of 0.58 ha with ten rubble piles at the school of the THW in Hoya, Germany. Three victim performers were hidden in a sewer system under the rubble piles. Furthermore, a worn piece of cloth was placed within one rubble pile, in order to check whether the dogs would neglect correctly this false target. As in the first field test, two runs were performed, but FRIEDAA assisted in both of the cases.

During the first run only biologic search was performed after a exploration phase. There were two exploration teams who covered the whole area during $16 \mathrm{~min}$. Two search dog teams were employed to search the whole area. After 27 min all victims were found. In one situation, a direct access to the victim could not be achieved. The search team suggested the application of technical search methods which, however, were not allowed during the first run. The total duration of the first run was 43 min with 93 distinct messages.

The second run was managed by the SEEBA team members. The same scenario as in the first run was used, but assistive technical search assets were available such as the bioradar, a SearchCam 3000 and the semi-active video-endoscope. The total duration of the exploration phase also performed by two teams was $25 \mathrm{~min}$. The search of two search dog teams lasted 28 min. The search dogs indicated correctly all locations of the victims. However, since technical search assets were available, they were used to verify the positions where dogs had indicated a victim. One victim that was trapped under stacked concrete slabs could be located thanks to the video-probe (Fig. 9b). In this case, biologic search (Fig. 9a) and the SearchCam (Fig. 9c) could not produce evidence about the victim position. The 


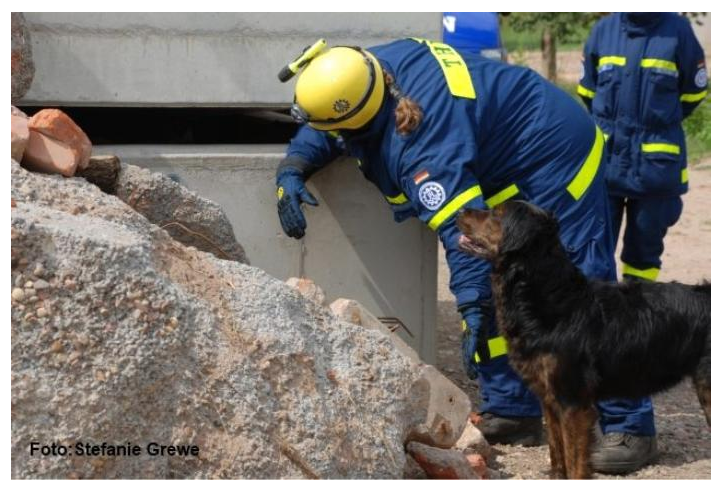

(a) Biologic search.

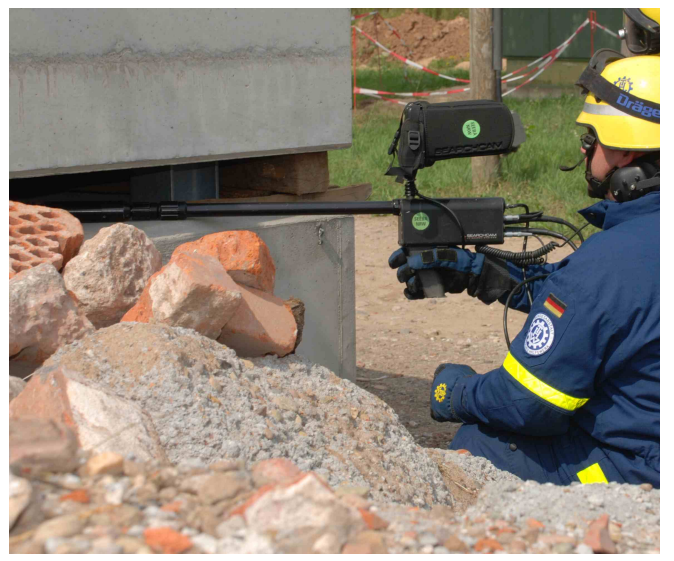

(c) Rigid video endoscope (SearchCam 3000).

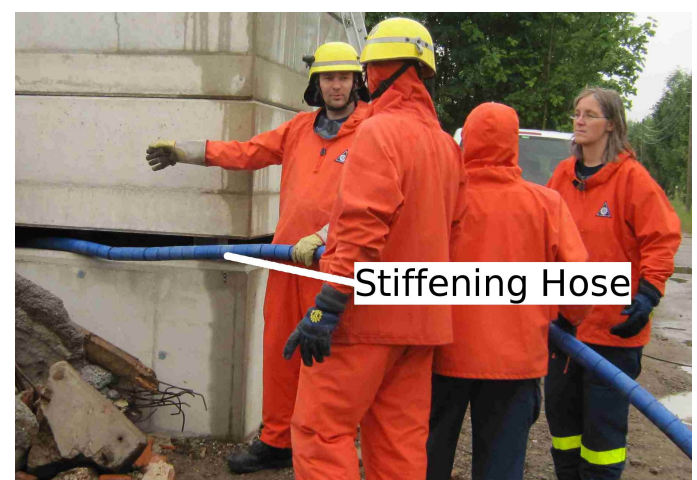

(b) Semi-active video probe.

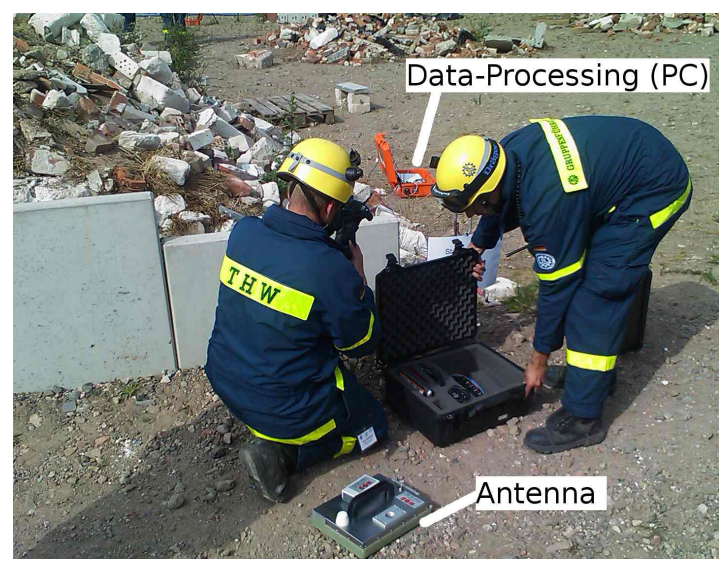

(d) Ground-penetrating radar for movement detection

Figure 9: Synergy between biologic and technical search methods.

other two victims were both successfully verified with the bioradar. After extrication of one victim, the bioradar device was employed once again to clear the area. The situation after the search phase gathered in FRIEDAA is presented in Fig. 10. The duration of the second run was 77 min with a total of 54 messages.

The operational progress of both runs is presented in Fig. 11. It shows that the longer total duration of the second run is mainly due to the employment of technical search means. The difference in message volume is due to the fact that during the first run, more hypothetic hazards ( $\Delta N_{\text {mes }}=+15$ messages), more destruction zones $\left(\Delta N_{\text {mes }}=+29\right.$ messages $)$ and less details about affected persons $\left(\Delta N_{\text {mes }}=-8\right.$ messages) were collected than in the second run. A comparison of the performance of the two runs is presented in Table 2 .

The performance of search activities can be expressed in how fast an area is cleared, i.e., the spatial search performance. The performance for human exploration and biologic search in a heavily destroyed area is $1.4 \mathrm{ha} / \mathrm{h}$ and $1.1 \mathrm{ha} / \mathrm{h}$, respectively. These numbers are the mean over both runs of the second field test. It is worth noting that the spatial search performance of the biologic search method consists of covering the whole area twice with two different dogs. 


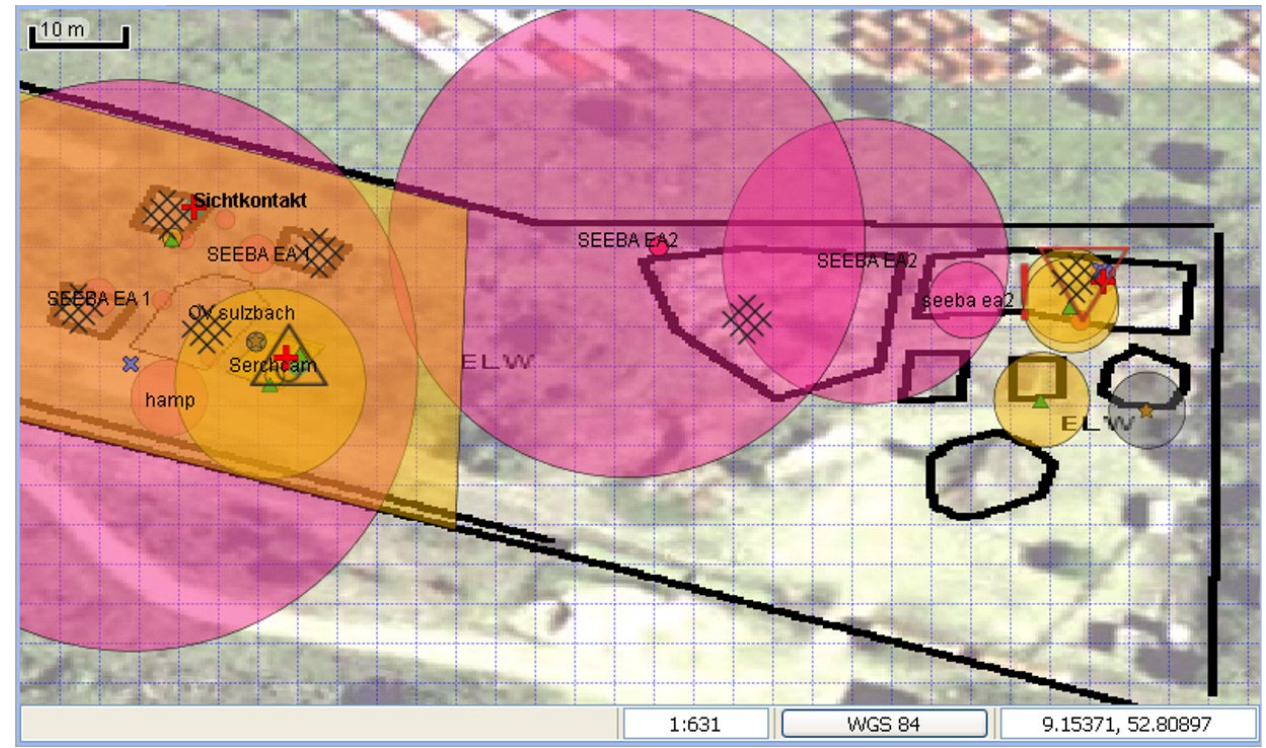

Figure 10: Representation of the operational progress in FRIEDAA after the field test with assistive search technologies. The colored areas represent searched zones or hazardous zones. The icons indicate the position of positive search results, positions where victims have been rescued, completely destroyed buildings, etc..

\subsubsection{Evaluation of the robot Moebhiu² ${ }^{2}$}

The robot has been tested at the simulated disaster site in Hoya. The robot has been used in two different settings to evaluate its maneuverability and its terrainability.

In the first setting, the robot has been steered by a single emergency workforce through a sewer system to search for the victim performers. The sewer system $(\varnothing 0.7 \mathrm{~m}$, see Fig. 1a) presented demanding requirements with regard to maneuverability since the robot had to overcome a descending and an ascending step of $0.2 \mathrm{~m}$ while turning around a curve with a maximum permitted radius of $0.8 \mathrm{~m}$. The robot's mobility was sufficient to manage this setting.

In the second setting, the robot was used to explore a horizontally collapsed concrete slab structure (see Fig. 12a). In this type of setting the following characteristic capabilities have been successfully

Table 2: Performance of the two runs evaluating the assistive search technologies with FRIEDAA assistance.

\begin{tabular}{|l||l|l|l|l|}
\hline Run & $\begin{array}{l}\text { Avg. Re- } \\
\text { Ports } \\
\text { Victim }\end{array}$ & $\begin{array}{l}\text { Avg. Time } \\
\text { First DeteC- } \\
\text { Tion }[\mathrm{min}]\end{array}$ & $\begin{array}{l}\text { Avg. Mes- } \\
\text { SAges }\left[\mathrm{min}^{-1}\right]\end{array}$ & $\begin{array}{l}\text { Total Search } \\
\text { Time }[\mathrm{min}]\end{array}$ \\
\hline \hline Conventional & 1.3 & 21.7 & 2.16 & 43 \\
\hline $\begin{array}{l}\text { Assistive SeARCH } \\
\text { Tech. }\end{array}$ & 4.0 & 24.0 & 0.69 & 77 \\
\hline
\end{tabular}




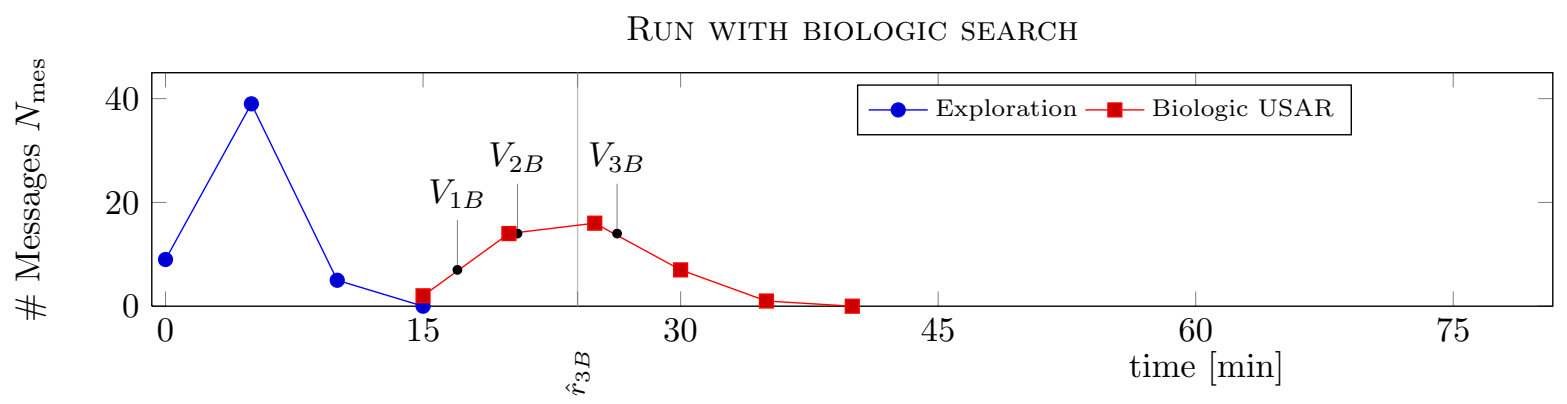

Run With ASSISTIVE TECHNOLOGIES

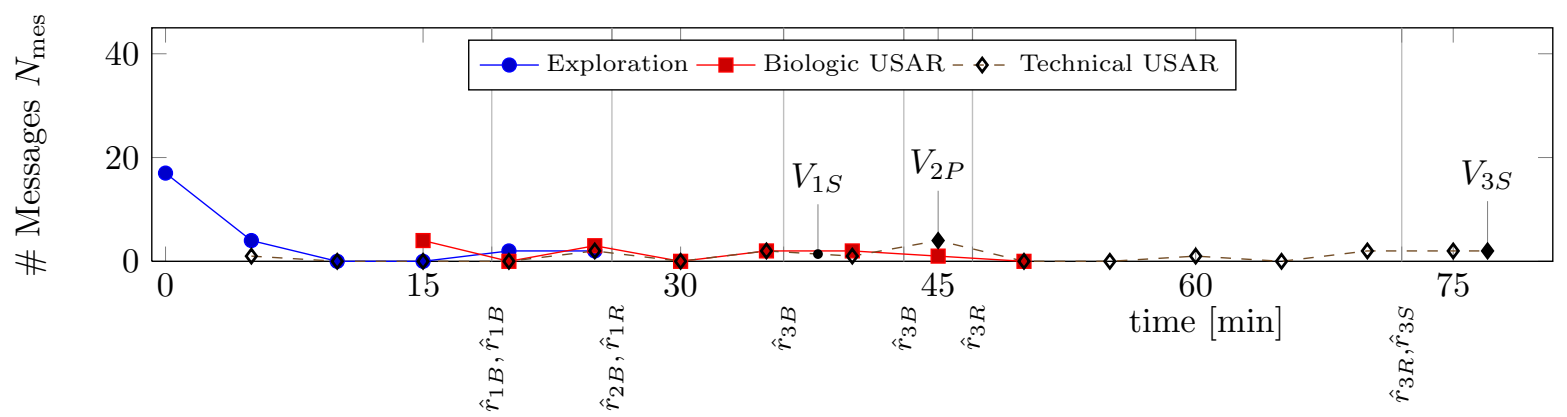

Figure 11: Operational progress of the USAR operations with three trapped victims with respect to the messages of phases: Exploration, Biologic USAR, and Technical USAR. The timestamps of all collected reports $\left(\hat{r}_{i x}\right)$ and victims $\left(V_{i x}\right)$ are represented relative to each victim $(\mathrm{i}=1,2,3)$ and employed method $(\mathrm{x}=$ SearchCam $(\mathrm{S})$, Video Probe (P), Biologic Search (B), Bioradar (R)).

evaluated such as propagation through narrow path height, negotiating a steep slope $\left(40^{\circ}\right)$, climbing backwards to another level of the debris cone and overcoming gaps. The best performances are summarized in Table $12 \mathrm{~b}$.

All these tasks have been satisfyingly fulfilled in the given test site.

\section{Lessons Learned: Technical search means applied by German rescue forces}

In Germany, USAR compared to surface search of lost persons only represents $5 \%$ of all SAR operations (statement of a canine SAR team of the THW). The SAR team members appreciated particularly the capability of FRIEDAA to show the cleared surfaces. They stressed that FRIEDAA would increase the surface search efficiency. The presented field tests partially allowed to evaluate the efficiency enhancement of the assistive technology of the I-LOV components. In an online survey about their experiences, rescuers stated in average that FRIEDAA represents an advantage for USAR operations. They all agreed that FRIEDAA has the potential to be ameliorated in such a way that its usage would be beneficial in real catastrophes. A key improvement would be the extension of bidirectional communication between EOC and on-site emergency workforces. 


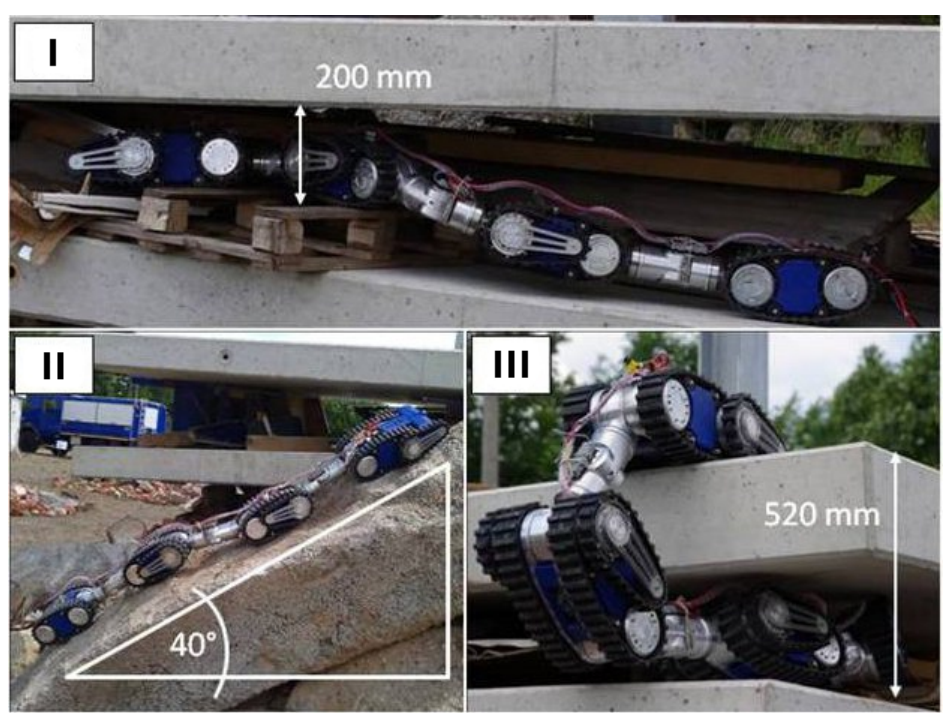

(a) Scenarios: (I) narrow path, (II) steep slope, and (III) backward climbing.

\begin{tabular}{|l||l|}
\hline PArameter & VAlue \\
\hline \hline Min. path width & $0.3 \mathrm{~m}$ \\
\hline Min. path height & $0.2 \mathrm{~m}$ \\
\hline Min. radius yaw & $0.6 \mathrm{~m}$ \\
\hline $\begin{array}{l}\text { Min. radius pitch } \\
\text { (backward climb) }\end{array}$ & $0.25 \mathrm{~m}$ \\
\hline Max. slope & $60^{\circ}$ \\
\hline Max. step size & $0.8 \mathrm{~m}$ \\
\hline $\begin{array}{l}\text { Max. gap width } \\
\text { (on flat surface) }\end{array}$ & $0.6 \mathrm{~m}$ \\
\hline
\end{tabular}

(b) Best Performances.

Figure 12: Mobility of Rescue Robot Moebhiu²s.

The simulation of extrication operations is difficult. A realistic training situation would endanger victim performer and represents a major time investment of $10 \mathrm{~h}$ in average [2]. This is the reason why the extrication phase could not properly be simulated during the here presented field tests. We expect that with a proper simulation of extrication efforts during field tests the expected increase of efficiency through more accurate localization due to assistive technologies could be demonstrated quantitatively.

Despite the fact that commercially available GPS receivers are insufficiently precise for victim localization, and also not acquirable indoors, the capability to store information with timestamps and geo-reference turned out to be very promising. Ongoing developments about Pedestrian Dead Reckoning [27] and $S L A M$ [28] will allow robust localization in all circumstances and enhance the capability to log operational progress in complex three dimensional terrain.

Conventional maps of operational progress such as presented in Fig. 3 are poor in content and functionality compared to GIS supported maps such as delivered by FRIEDAA (see Fig. 10). Long lasting operations in complex, multi-storied terrain are certainly manageable on paper media. However, the capability to search and filter information with respect to temporal timestamps and categories are the clear advantages of digital assisted search. The data logging capability of digitally assisted search fosters the consolidation of experiences in the field, which is important for improving the efficiency of USAR missions in the future.

The benefits of non-verbal digital transmission of messages became evident through the first field test. In the first run with conventional methods, the two persons in the EOC reached their limit to handle the amount of incoming messages. In the second run, more information was transmitted whereas the two persons in the EOC had nearly no work and would have been able to focus on other important tasks such as warning endangered workforces, assessing uncertain information and managing 
the list of missing persons. The WLAN communication infrastructure was lacking of coverage within and behind buildings during the first field test. The lack of coverage caused delays. However, this can be remedied with other digital radio communication technology such as GSM or TETRA [29]. If such an infrastructure is used to entirely cover a terrain such as during the second field test, delays become negligible.

The comparison in Fig. 11 shows that the assistive technology used during the second run increased the total duration of the search phase. However, it is worth noting that during USAR missions precise victim localization is of top most importance, which can be gained by assistive technologies as proved by the performance comparison in Table 2. If the position is only known vaguely, extrication efforts thus the total rescue duration might considerably increase.

The SEEBA stressed the importance of portability of the assistive technologies. The bioradar was particularly promising in this regard. It proved to be a valuable tool for detection of victims in rubble that are unable to alert rescuers. In the future, the system shall be enhanced by being able to localize a victim. Information such as distance and direction with respect to antenna position might allow to estimate the extrication efforts. Further tests need to be carried out to show the versatility of the bioradar with respect to various types of debris.

The search probe allowed a hitherto unreachable penetration depth. The navigation pane with two artificial horizons are important for the rescuers to orientate themselves within the rubble pile. A good coordination between the emergency workforce pushing the hose and the one controlling its stiffness and the navigation from the head joints is required.

The evaluation of the rescue robot focused on terrainability which was convincing. In a laboratory setting even a wooden slope of $60^{\circ}$ and a curve with a outer radius of $0.6 \mathrm{~m}$ was handled by Moebhiu ${ }^{2} \mathrm{~s}$. The ability of climbing high steps, turning in narrow spaces, and even backward climbing from one level to another is nearly exclusive to snake-like robots due to their ability to bend their body, adapt their center of gravity and, of course, to their length compared to conventional robots (e.g., $[19,30])$. However, snake-like robots' control is more complex. In order to disburden the human operator, semi-autonomy has to be provided such as the one of Moebhiu² s enabled by tactile sensors integrated in the tracks.

During the field test the robot was outperformed by other search methods and thus could not contribute to the timely detection of the victim performers. Since no hazardous area was simulated which in real disaster situation are likely, its potential could not be demonstrated.

In real scenarios several issues may arise which would need to be handled by Moebhiu ${ }^{2}$ s. A very simple example is the opening of doors as presented by Kobayashi et al. [31]. Furthermore, in confined space tethered robots are limited. The WLAN connection to the robot in the sewer system of the simulated disaster site in Hoya was evidently limited to a few meters away from the entry point in the ground shown in Fig. 1a. Therefore, a tethered version of the robot was used. Alternative solution with WLAN repeaters as presented by Ferworn et al. might be investigated [32].

The assistive search technologies have shown to be trustful tools that increase certitude about victim presence and location. The search technologies in the given circumstances of the field test in Hoya always 
correctly indicated the presence of a trapped victim.

\section{Conclusions}

The assistive search technologies all contributed to more effective search. The synergy with biologic search proved to give more accurate results with respect to certainty of presence, location accuracy, and situation awareness. The assistive IT-system enabling digital communication of messages proved to be a valuable tool. It not only enhanced the message volume from on-site rescuers improving the situational awareness in the EOC, but also enabled the EOC to focus on other tasks such as surveillance by disburdening it from the logging task. Even if the duration of the field tests assisted with the new technologies lasted a bit longer, it is expectable that the total duration will decrease with proper training and with additional improvement of the new technologies' ergonomics. In the future, a significant amount of field tests with proper simulation of extrication operations might provide the proof that the new technologies increase globally the efficiency of USAR missions.

\section{Acknowledgment}

We gratefully acknowledge financial support from the German Federal Ministry of Education and Research (support code: 13N9759). Furthermore, we are most grateful for the support of the German Federal Agency for Technical Relief (THW), of SEEBA, of RIF e.V. and of the companies JT-electronic

$\mathrm{GmbH}$, carat robotic innovation GmbH, Berlin- Oberspree Sondermaschinenbau GmbH (BOS). FRIEDAA uses uDig source code of Refractions Research.

\section{References}

[1] Andrew Coburn and Robin J. S. Spence. Earthquake Protection. John Wiley and Sons, 2002.

[2] Fritz Gehbauer, Susanne Hirschberger, and Michael Markus. Methoden der Bergung Verschütteter aus zerstörten Gebäuden, volume 46 of Zivilschutz-Forschung Neue Folge. Druckhaus Dresden GmbH, Bonn, Germany, 2002.

[3] S. Tadokoro. Problem domain of Japan national project (DDT project) on rescue robotics. In Second International Workshop on Synthetic Simulation and Robotics to Mitigate Earthquake Disaster (SRMED 2004), 2004.

[4] Louise K. Comfort, Kilkon Ko, and Adam Zagorecki. Coordination in rapidly evolving disaster response systems: The role of information. American Behavioral Scientist, 48:295-313, 2004.

[5] Bundesamt für Zivilschutz, Bonn, Germany. Der Bergungseinsatz bei Gebäudeschäden, 1986. 
[6] M. Neumann, P. Labenda, T. Predki, and L. Heckes. Snake-like, tracked, mobile robot with active flippers for urban search-and-rescue tasks. In Proceedings of the 15th International Conference on Climbing and Walking Robots and the Support Technologies for Mobile Machines (CLAWAR), Baltimore, USA, 2012.

[7] S. Zorn, M. Maser, A. Goetz, R. Rose, and R. Weigel. A power saving jamming system for EGSM900 and DCS1800 cellular phone networks for search and rescue applications. In IEEE Topical Conference on Wireless Sensors and Sensor Networks (WiSNet), 2011.

[8] O. Rogall, R. Schilling, M. Loschonsky, R. Schimko, and L. M. Reindl. Radargestützte Personenortung. In Sensoren und Messsysteme, pages 728-732, Nürnberg, 2010. VDE. (engl.: Radar based localization of persons).

[9] Quirin Hamp, Michael Eitelberg, Bo-Sik Lee, Tobias Becker, Dirk Wiebeck, and Leonhard Reindl. Information Fusion based on graph analysis during Urban Search and Rescue. In Information Fusion, Edinburgh, UK, 2010. IET.

[10] Quirin Hamp, Denise Güthlin, and Leonhard Reindl. Decision Behavior during Urban Search and Rescue - A German Case Study. Disasters Journal, 2012. accepted for publication.

[11] P. Maack. Die Systematik der Schadenstellen, I. Teil. Baulicher Luftschutz, 6(5):97-118, 1942.

[12] P. Maack. Die Systematik der Schadenstellen, II. Teil. Baulicher Luftschutz, 6(6):129-133, 1942.

[13] P. Maack. Die Systematik der Schadenstellen, III. Teil. Baulicher Luftschutz, 7:2-16, 1943.

[14] Ulf Tabbert and Jörg Meike. Maßnahmen der Feuerwehr und anderer Hilfskräfte nach Gebäudeeinstürzen. Vereinigung zur Förderung des Deutschen Brandschutzes (vfdb), 2003.

[15] Jennifer Casper and Robin Murphy. Human-Robot Interactions During the Robot-Assisted Urban Search and Rescue Response at the World Trade Center. IEEE Transactions on Systems, Man, and Cybernetics-Part B: Cybernetics, 33(3):367-385, 2003.

[16] Bundesanstalt Technisches Hilfswerk, Bonn, Germany. THW DV1-102 Taktische Zeichen, 2000.

[17] K. Hatazaki, M. Konyo, K. Isaki, S. Tadokoro, and F. Takemura. Active scope camera for urban search and rescue. In International Conference on Intelligent Robots and Systems (IROS 2007), pages 2596-2602. IEEE/RSJ, 2007.

[18] R. R. Murphy, S. Tadokoro, D. Nardi, A. Jacoff, P. Fiorini, H. Choset, and A. M. Erkmen. Search and Rescue Robotics, chapter 50. Springer, Berlin, New York, 2008.

[19] Aaron Johnson, Matthew Hale, G. Haynes, and Daniel Koditschek. Autonomous Legged Hill and Stairwell Ascent. In Int. Symposium on Safety, Security, and Rescue Robotics, Kyoto, Japan, 2011. IEEE. 
[20] Keiji Nagatani, Seiga Kiribayashi, Yoshito Okada, Satoshi Tadokoro, Takeshi Nishimura, Tomoaki Yoshida, Eiji Koyanagi, and Yasushi Hada. Redesign of rescue mobile robot Quince. In Int. Symposium on Safety, Security and Rescue Robotics, Kyoto, Japan, 2011. IEEE.

[21] N Saga, T Nakamura, and S Ueda. Study on peristaltic crawling robot using artificial muscle actuator. In PROCEEDINGS OF THE 2003 IEEE/ASME INTERNATIONAL CONFERENCE ON ADVANCED INTELLIGENT MECHATRONICS (AIM 2003), VOLS 1 AND 2, IEEE ASME International Conference on Advanced Intelligent Mechatronics, pages 679-684, 345 E 47TH ST, NEW YORK, NY 10017 USA, 2003. IEEE Ind Elect Soc; IEEE Robot \& Automat Soc; ASME Dynam Syst \& Control Div, IEEE. IEEE/ASME International Conference on Advanced Intelligent Mechatronics, KOBE, JAPAN, JUL 20-24, 2003.

[22] Tetsushi Kamegawa, Toshimichi Baba, and Akio Gofuku. V-shift control for snake robot moving the inside of a pipe with helical rolling motion. In Int. Symposium on Safety, Security, and Rescue Robotics, Kyoto, Japan, 2011. IEEE.

[23] Hajime Asama, Yasushi Hada, Kuniaki Kawabata, Itsuki Noda, Osamu Takizawa, Junichi Meguro, Kiichiro Ishikawa, Takumi Hashizume, Tomowo Ohga, Michinori Hatayama, Fumitoshi Matsuno, and Satoshi Todokoro. Rescue infrastructure for global information collection. In 2006 SICE-ICASE International Joint Conference, Vols 1-13, pages 1600-1605, 2006.

[24] Jun-Ichi Meguro, Kiitirou Ishikawa, Takumi Hasizume, Jun-Ichi Takiguchi, Itsuki Noda, and Mitinori Hatayama. Disaster information collection into geographic information system using rescue robots. In 2006 IEEE/RSJ International Conference on Intelligent Robots and Systems, volume 1-12, pages 3514-3520, 2006.

[25] J. Hightower and G. Borriello. Location systems for ubiquitous computing. Computer, 34(8):57-66, 2001.

[26] Eduardo F. Nakamura, Antonio A. F. Loureiro, and Alejandro C. Frery. Information fusion for wireless sensor networks: Methods, models, and classifications. ACM Computing Surveys, 39(3), 2007.

[27] R. Zhang and L.M. Reindl. Pedestrian motion based inertial sensor fusion by a modified complementary separate bias Kalman filter. In Sensors Applications Symposium (SAS), pages 209-213. IEEE, 2011.

[28] Alexander Kleiner, Christian Dornhege, and Sun Dali. Mapping disaster areas jointly: RFIDcoordinated SLAM by humans and robots. In International Workshop on Safety, Security and Rescue Robotics, pages 42-47, NEW YORK, USA, 2007. IEEE.

[29] Peter Stavroulakis. Terrestrial trunked radio - TETRA: a global security tool. Springer, 2007. 
[30] Q. Zhang, S. S. Ge, and P. Y. Tao. Autonomous Stair Climbing for Mobile Tracked Robot. In Int. Symposium on Safety, Security, and Rescue Robotics, Kyoto, Japan, 2011. IEEE.

[31] Shigeru Kobayashi, Yoshikazu Ohtsubo, Hidetake Iwasaki, Yasuhiro Kobayashi, and Toshi Takamori. Features of UMRS2009 Special Components. In Int. Symposium on Safety, Security, and Rescue Robotics, Kyoto, Japan, 2011. IEEE.

[32] Alexander Ferworn, Nhan Tran, James Tran, Gerry Zarnett, and Farrokh Sharifi. WiFi repeater deployment for improved communication in confined-space urban disaster search. In INTERNATIONAL CONFERENCE ON SYSTEM OF SYSTEMS ENGINEERING, volume 1 and 2, 2007. 